\title{
Social media, sustainability, and environmental protection in sustainable education
}

\author{
Mihaela Simionescu ${ }^{1.2^{*}}$, Zuzana Horváthová ${ }^{3}$, Nataliia Kovshun ${ }^{4}$, and Nina Kushnir ${ }^{4}$ \\ ${ }^{1}$ University of Social Sciences, Harcmistrza Aleksandra Kamińskiego 21, 90-229 Lodz, Poland \\ ${ }^{2}$ Institute for Economic Forecasting of the Romanian Academy, 050711 Bucharest, Romania \\ ${ }^{3}$ Metropolitan University Prague, 10000 Dubečská str., 900/10, Prague, Czech Republic \\ ${ }^{4}$ National University of Water and Environmental Engineering, Soborna str., 11, 33000 Rivne, \\ Ukraine
}

\begin{abstract}
This paper focuses on the perceptions of sustainability and environmental protection expressed by the users of social networks (such as Facebook or WhatsApp). Forming the perception of climate change and environmental protection is a part of sustainable education. Social networks and Internet-based technologies might contribute to the process of gaining, processing and exchanging the information on sustainable development and to help to shape the social environmental awareness. Our results demonstrate that people who are familiar with the concept of sustainability consider environmental protection to be very important compared to those who are not familiar with this concept. In addition, it appears that people without any significant knowledge about sustainability are not interested in environmental protection. These outcomes suggest that sustainable education might help people in changing their perspectives and considering environmental protection to be essential for the future.
\end{abstract}

\section{Introduction}

Sustainable development became a global trend for the $21^{\text {st }}$ century. With the pressing environmental issues such as worldwide pollution, global climate change and environmental degradation, everyone now needs to be aware of sustainability [1,2]. However, it might often not be such a case, since sustainable education does not have the capacity to penetrate into each level of each educational establishments in each country of the world [3, 4]. Moreover, the rising popularity of Internet technologies and the social networks might help the humanity to partially solve this problem.

The 2030 Agenda for Sustainable Development sets globally negotiated targets for achieving sustainable development. The economic aspect of sustainability implies a reduction in current consumption levels without jeopardizing future needs [5,6]. It is also about preserving the health and well-being of the environment, as well as human rights and human dignity. Our research assumes that the answer to this question depends very much on how sustainability is defined and how the terms sustainable and sustainable sustainability are

* Corresponding author: mihaela_mb1@yahoo.com 
clarified in a global context. This research paper examines the role of science in generating knowledge to support the transformation of sustainable development and analyses how theories and changes can help in sustainability science. The impact of the Sustainable Development Goals (SDGs) and their carry-over effects are crucial for sustainability. If we want a future, we should demand a holistic, integrated approach to sustainable development that encourages humanity to live in harmony with nature and restore the health and integrity of the Earth's ecosystems [7,8]. Accordingly, the fourteen Sustainable Development Goals (SDGs), presented to the United Nations General Assembly in August 2014, include the Sustainable Development Goal (SDG14) which aims to conserve and use oceans, seas and marine resources for sustainable development. In this context and in others, it stresses the importance of the use of all oceans and seas resources for the sustainability of sustainable development, including sustainable economic growth and the protection of biodiversity and biodiversity - rich ecosystems. Issues relating to oceans or seas must be dealt with in accordance with the UN Convention on the Conservation of Natural Resources (CNR) and other international treaties $[9,10]$. The term "sustainable development" has come to the fore as a mantra and swear word since its introduction by the UN-sponsored World Commission on Sustainable Development (WCED) in 1997. The inherent vagueness of core concepts is shared by many other international organizations, such as the United Nations, the World Bank, and the International Monetary Fund. But their definitions of "sustainable development" vary considerably in scope and scope, and in their impact on people's lives.

Generally, sustainable development is a difficult concept to define, but it is generally believed to have three components: environment, society, and the economy. One of the original descriptions of sustainable development was attributed to the Brundtland Commission. Sustainable development has evolved over the years, making its definition doubly difficult $[11,12]$.

A healthy and prosperous society, for example, depends on a healthy environment to help its citizens. Environmental sustainability aims to improve people's wellbeing by improving the quality of life for all people, not just the most vulnerable among us.

What can we do and what can we do to combat the threats to the environment that can damage people's health, livelihoods and lives? China might be a good example. The country is often labelled as one of the major players in worldwide environmental pollution. No wonder about that - since many world's manufacturing industries are now based in China, the country is a major producer of $\mathrm{CO} 2$ and other greenhouse gases [13, 14]. In order to tackle this issue, the Chinese government has formulated appropriate research programs and plans for all major environmental research areas to organize forces to address major scientific and technological problems. China is also expanding its research and developing new environmental technologies, such as wind and solar energy, biofuels and biogas.

The project is supported by the Chinese Ministry of Environmental Protection and the National Academy of Sciences of the People's Republic of China (NAC). Environmental protection is an ideology that calls for the respect, protection and protection of the natural world from human - anthropogenic - suffering. Environmental awareness is imbued with the ability to understand the fragility of the environment and the importance of protecting it. Promoting environmental awareness was an easy way to become an environmentalist and to participate in creating a better future for our children. If we teach our friends and family that the physical environment is fragile but indispensable, we can begin to solve the problems that threaten them by teaching them the importance of environmental protection. Environmental protection is a shared responsibility of all of humanity, and economically developing countries should take more responsibility in this regard $[15,16]$. China consistently believes that economic development should be coordinated with environmental protection. To address its own environmental problems and take a more active role in developing global environmental protection, China is actively participating in and supporting environmental 
activities initiated by United Nations organizations, participating in international environmental cooperation, and making efforts to promote global environmental protection as a "shared task" for humanity [17].

\section{Protection of natural resources}

One would probably agree that our society is committed to identifying, developing and implementing through governance technological, economic, political and social measures that create the conditions for the future of natural resources and their management. The humanity is doing this today - it is continuously adding knowledge and tools and it has the ability to manage water resources with the help of technology at a much higher level than in the past.

For example, preserving water-dependent ecosystems such as rivers, lakes, streams and wetlands is very important. This requires an understanding of the interdependence of all components of such systems and will also be necessary for the management of water resources in the future. But the use of ever-increasing natural resources comes at a price, and our current management policy must be examined in terms of where more people want and where they can afford more [18]. If we lose large parts of the natural world, the quality of human life will be severely reduced and the lives of future generations threatened unless effective action is taken. Adaptation requires a range of measures, such as plant breeding to cope with higher temperatures, establishing water conservation systems, and changing production systems where climate change makes it impossible to grow certain crops. Plants have too few pollinators, soils are depleted, air and water quality are poor and coasts are less protected from storms. To avoid these outcomes, productivity gains must be explicitly linked to protecting natural ecosystems from the switch to agriculture. Governments, financiers, and others can make low-interest loans conditional on protecting forests, as, for example, Brazil has done, and ensure that infrastructure investment does not come at the expense of ecosystems. Improved agricultural productivity and better management of natural resources such as water can save forests and savannahs worldwide, but that is not enough. Innovative investments in technologies in irrigated environments are needed to achieve a more productive use of water in agriculture [19].

This would improve risk management in agriculture, especially for smallholder farmers, and would be crucial to enable farms and households to adopt new technologies, diversify their activities, and maintain food security in the face of climate change and other livelihood threats. Most pathways to sustainable development are water-related, but water managers alone do not make the decisions that determine whether water resources are used or misused [20]. As discussed later in this paper, decision-making and support models today are unlikely to produce the best solutions for water management, even if they are supported by decisionmaking democracy. This is a central issue that begins with the need to adopt socio-economic development goals and formulate policy and operational decisions to achieve them.

Water resource managers must meet the demands of water use in a way that is fit for life - to maintain the demands, create livelihoods and support them. Decisions that respond to living and livelihood needs must be implemented without externalities, often without direct control, that interact with and alter the drivers of change, putting pressure on land and water resources. The United Nations Conference in Stockholm in 1972 underlined the importance of preserving and improving the environment and its biodiversity in guaranteeing human rights and a healthy, productive world. The world has taken the view that achieving sustainable development in the twenty-first century is not an option, but a necessity. It is vital that everyone takes the depletion of natural resources seriously and does everything in their power to preserve their environment. It is time for people to start learning, inventing and implementing sustainable environmental practices [21]. We can all do our bit to protect the 
environment by reducing electricity consumption, carpooling with colleagues and recycling, to name a few. Companies are regulated to keep carbon emissions down, and governments are now trying to incentivize people to install renewable energy sources in their homes. This also has to be connected to such issues as proper business ethics, fighting corruption, maintaining social corporate responsibility and proper mass media coverage [22, 23, 24]. As the equatorial regions gradually become depopulated, more stable northern nations develop. Automated robots are programmed to extract and process useful materials from decaying infrastructure. Phosphorus reserves are safe because even abundant sources of low quality can be extracted. Whole cities are being abandoned because of climate change, and we are taking advantage of the fact that the remaining local population is benefiting.

How can increased use of digital technologies contribute to a more sustainable future, both in terms of their impact on the environment and human health? Despite progress in some areas, the world is unlikely to meet most of these targets by 2030 . How can people learn about these 17 global goals so that they can effectively support the Sustainable Development Goals? As the world struggles to meet the United Nations Sustainable Development Goals (SDGs), the need for reliable data to track progress is more important than ever. This is where sustainable education becomes important. One can use facts and figures to inform people about the importance of goals and focus on promoting one or two specific goals at the same time $[25,26]$. Although education is crucial, everyone needs to launch own social media campaign with educational content that will inform people about the Sustainable Development Goals.

\section{Materials and methods}

In order to establish the grounds and prerequisites of the perceptions of sustainability and environmental protection expressed by the users of social networks (such as Facebook or WhatsApp), a questionnaire was developed to register people's opinion on sustainability and environment protection.

The questionnaire was applied to a group of Romanian respondents using social media channels (Facebook and WhatsApp). The responses of 420 people were registered and recorded even though the sample was not representative for the Romanian population. The main aim was to develop a volunteer-based survey to get a picture related to some Romanian opinions about environmental concepts. Beside demographic variables related to age, gender, marital status and group of income, we employed some qualitative variables to express the opinions. The associated questions in the questionnaire and responses are presented in the next section.

In order to establish a link between teaching and learning the concept of sustainability and the awareness of the pressing issues our planet faces, we would also employ a multinomial logistic regression used for explaining the attitude related to the importance of environmental protection. The explanatory variables refer to the knowledge of the concept of sustainability and the respondent's age is used as the control variable. We are using a Likert scale-type gradation for measuring people's attitudes (very important, important, neutral, not so important, totally unimportant). The results and their discussions are presented below in the next section.

\section{Results and discussions}

We asked our respondents a number of questions and recorded their answers. Question 1 (Q1) asked about the extent to which the respondents knew or were aware of the concept of sustainability. It reads as follows: 
Q1. To what extent do you know the concept of sustainability?

a. Very well;

b. Well;

c. Little bit;

d. Not at all.

Figure 1 that follows, shows the division of the respondents' knowledge related to their perception of sustainability.

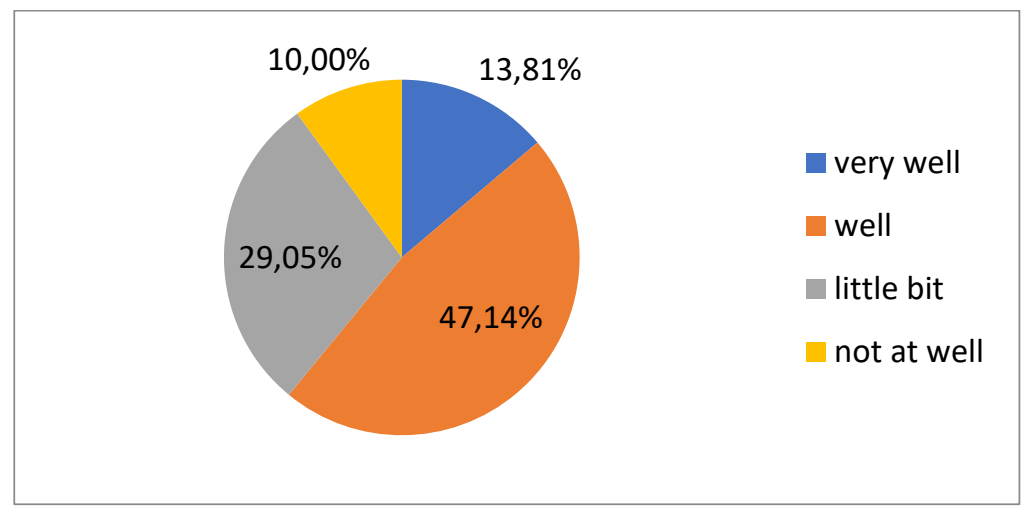

Fig. 1. Respondents' knowledge about the concept of sustainability

As one can observe from Figure 1, about $90 \%$ of the respondents who took part in our survey, have some knowledge about the concept of sustainability and only $10 \%$ do not know anything about this subject. The result indicates that the concept of sustainability has a place in the collective mentality. It also might mean that many people actually heard the term but are not really sure what it means and cannot provide an exact or at least concise definition of what it all might be about.

Question 2 (Q2) inquired about the danger of running out of the natural resources in the near future. It was formulated as follows:

Q2. Do you think that the natural resources are in danger of running out in the near future?
a. Yes;
b. No;
c. I do not know.

The question attempted to find out whether the respondents were aware of the issues that our natural resources present. The dependence of the fossil fuels led to the massive environmental pollution and other issues such as the global climate change. Hence, a shift of paradigm is required helping people to break the old stereotypes and to shift from the old and obsolete sources of energy to the new renewable energy sources powered by sun, wind, hydro, or biomass.

Figure 2 that follows, summarizes our findings from the replies of the respondents. 


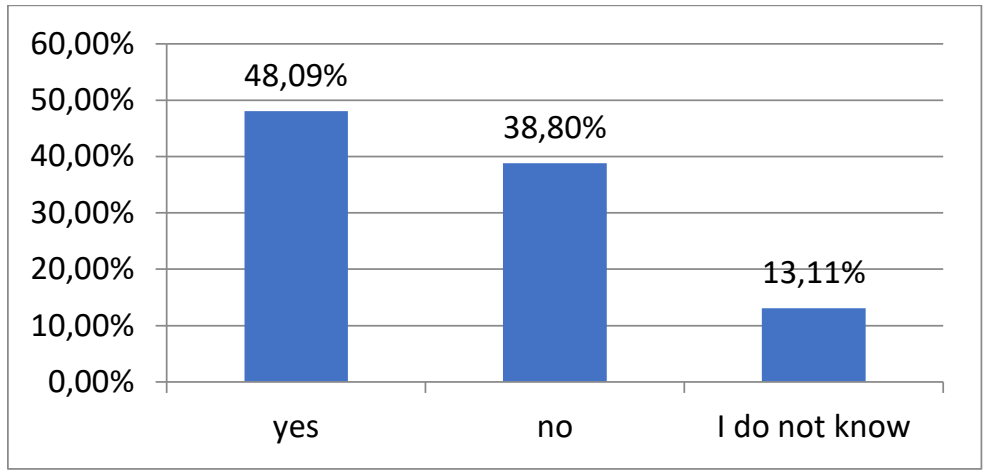

Fig. 2. Respondents' knowledge about the depletion of natural resources

As one can see from the results presented in Figure 2, almost half of the respondents strongly believe that the natural resources will run away in the near future. This result suggests a serious awareness about the sustainable future of the natural environment.

The next question $(\mathrm{Q} 3)$ read like the following:

Q3. How important is for you the environmental protection?
a. Very important;
b. Important;
c. I have a neutral opinion;
d. Not so important;
e. Totally unimportant.

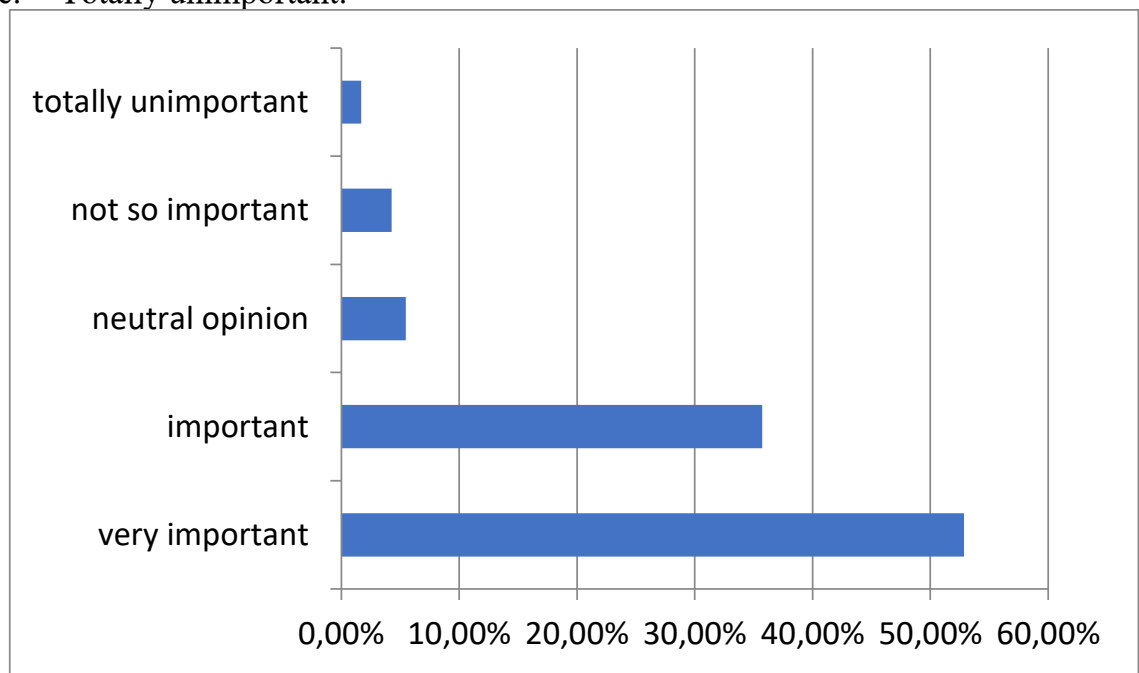

Fig. 3. Respondents' opinions about the importance of environmental protection

As Figure 3 shows, a total of $88.56 \%$ of the respondents confirm the importance of environmental protection for achieving the sustainable development objectives. Only few people were not really interested in this topic and considered it to be totally unimportant or irrelevant.

The key to achieving the SDGs is to connect activists with the resources and support they need. That is precisely what development experts have achieved through the use of social media as a tool for developing sustainable development initiatives. The dissemination of programs that make a difference and educate more people about the SDGs is crucial in this regard. A large number of people who engage in this way, even if only through social media, 
will continue to advance progress toward the Sustainable Development Goals. Harnessing the power of the Internet and social media can help us overcome the obstacles to sustainable nature tourism and development

The key role that the media can play is to help establish links between experts and readers of civil society and to raise awareness of sustainable development issues. According to some researchers, social media represents an ideal platform to fill the gap between what companies and individuals perceive as performance and what they deliver in terms of achieving sustainable goals and environmental protection.

As an empirical model, a multinomial logistic regression was carried out using STATA 15 statistical software to explain the attitude related to the importance of environmental protection. The explanatory variables used in out model refer to the knowledge of the concept of sustainability and respondent's age which is used as the control variable. The results are presented in a neat comprehensive table (see Table 1) that follows below.

Table 1. Multinomial logistic regression to explain the importance of environmental protection

\begin{tabular}{|l|l|l|}
\hline Variants & Coefficient & $\mathrm{p}$-value \\
\hline Very important & & \\
\hline Age & 0.3883 & 0.012 \\
\hline Concept of sustainability & 1.2022 & 0.002 \\
\hline Constant & -0.8916 & 0.034 \\
\hline Important & & \\
\hline Age & 0.2589 & 0.042 \\
\hline Concept of sustainability & 0.9023 & 0.003 \\
\hline Constant & -1.2553 & 0.045 \\
\hline Not so important & & \\
\hline Age & 0.1432 & 0.048 \\
\hline Concept of sustainability & -0.2245 & 0.004 \\
\hline Constant & -2.5899 & 0.065 \\
\hline Totally unimportant & & \\
\hline Age & 0.1128 & 0.057 \\
\hline Concept of sustainability & -0.034 & 0.006 \\
\hline Constant & -3.2037 & 0.078 \\
\hline
\end{tabular}

According to the results presented in Table 1, people who know the concept of sustainability have more changes to consider important the environmental protection compared to those with a neutral opinion. On the other hand, people without significant knowledge about sustainability are not interested in environmental protection. This conclusion supports the hypothesis that the education on sustainability will help people in considering environmental protection as essential for the future.

\section{Conclusions and implications}

Environmental pollution is one of the most dangerous factors affecting the environment, and changes affecting ecosystems can threaten several species with extinction, which requires the protection of these species. The humanity is responsible for the care of our environment, and man has the responsibility to preserve nature and its characteristics. By protecting the environment, humanity is protecting humanity from the effects of climate change, pollution and other forms of environmental degradation. Biodiversity is an important part of life in the 
world and consists not only of the animals that live on earth, but also of forests, grasslands and tundra that are located to maintain the life cycle of ecosystems.

It is vital that we protect the environment by reducing the myriad anthropogenic activities that cause the destruction of the ecosystem. Environmental degradation is harmful because it threatens the health and welfare of people, animals and nature as a whole. It is more a moral obligation for man to protect our environment from pollution and other activities that lead to environmental destruction, such as the pollution of water, air and land.

The environmental problems we are currently facing, such as climate change, water scarcity, air pollution and biodiversity loss, are just some of the many environmental problems we face. Many of them are increasing due to human activities, not only in the United States, but also worldwide. In this essay, it can be argued that it is worth fighting for environmental protection for several reasons. Firstly, pollution is one of the main reasons why we should fight to protect the environment. In addition, warmer climate and floods also increase the chances of spreading pests and disease vectors. In addition, warm climatic changes such as floods also increase the chances of spreading pesticides and diseases, as well as the risk of disease. The Environmental Protection Agency (EPA) recognizes that the development of technology and biotechnology is the key to sustainability and that the environment of the future must be protected from the potential damage that technological advances could potentially cause. Environmental protection is a key component of the EPA's Sustainable Development Goals and such global and important organizations as the EPA. It defines how we all should study, protect and focus on the elements that pollute our environment. It is also about how technology will drive a greener future, such as the use of renewable energy, energy efficiency and clean energy.

Therefore, it appears crucial to increase the people's awareness of the climate changes, global environmental pollution and other ecological disasters. This can be effectively achieved through increasing the efforts channeled into the sustainable education. People who are informed about the principles of the sustainability and are environmentally educated, tend to understand the pressing issues Earth has to face in the $21^{\text {st }}$ century. It also appears that sustainable education can be successfully carried out using Internet and online tools such as social networks and social platforms. This shows that novel technologies can help us to contribute to saving the environment and achieving the principles of the sustainable development.

The goal of the social media should be to provide an evidence-based channel for the public, including members of the aviation community, civil society and other stakeholders, to discuss emerging problems and opportunities for sustainable development. We should encourage the use of public media to improve the agenda and promote engagement in the development of sustainable development initiatives. These are tools that should and must be used wisely for sustainable human development goals. Many civil society actors have recently underlined the importance of minimizing the use of social media as a tool for developing sustainable development initiatives. The discussions that have taken place since the adoption of the SDGs have made it clear that we have a responsibility to contribute to the achievement of these goals and the human development agenda.

\section{Acknowledgements}

This paper is the result of Metropolitan University Prague research project no. 74-03 "Public administration, legal disciplines and industrial property" (2020) based on a grant from the Institutional Fund for the Long-term Strategic Development of Research Organisations. 


\section{References}

1. K. Anderson, B. Ryan, W. Sonntag, A. Kavvada, L. Friedl, Geo-spatial Information Science, 20(2), 77 (2017)

2. S. Fukuda-Parr, Gender \& Development, 24(1), 43 (2016)

3. A. Sinha, T. Sengupta, Resources Policy, 63, 101413 (2019)

4. E. Lisin, D. Shuvalova, I. Volkova, W. Strielkowski, Sustainability, 10(4), 1111 (2018)

5. F. Schneider, A. Kläy, A. B. Zimmermann, T. Buser, M. Ingalls, P. Messerli, Sustainability Science, 14(6), 1593 (2019)

6. J. D. Sachs, G. Schmidt-Traub, M. Mazzucato, D. Messner, N. Nakicenovic, J. Rockström, Nature Sustainability, 2(9), 805 (2019)

7. V. Herrera, World Development, 118, 106 (2019)

8. J. H. Knox, Review of European, Comparative \& International Environmental Law, 28(1), 40 (2019)

9. W. Strielkowski, E. Lisin, I. Gryshova, Romanian Journal of European Affairs, 16(4), 68 (2016)

10. H. Janetschek, C. Brandi, A. Dzebo, B. Hackmann, Climate Policy, 20(4), 430 (2020)

11. Y. Aguila, Sustainability, 12(14), 5636 (2020)

12. S. Balitskiy, Y. Bilan, W. Strielkowski, Journal of Security \& Sustainability Issues, 4(2), 125 (2014)

13. J. Yuan, W. Li, J. Guo, X. Zhao, M. J. Skibniewski, International journal of environmental research and public health, 15(7), 1323 (2018)

14. Z. Zhang, M. Lis, Sustainability, 12(4), 1368 (2020)

15. Q. Qiao, F. Zhao, Z. Liu, H. Hao, Conservation and Recycling, 140, 45 (2019)

16. Q. Ji, D. Zhang, Energy Policy, 128, 114 (2019)

17. B. Lin, Y. Chen, Energy Economics, 78, 259 (2019)

18. R. Bolpagni, S. Poikane, A. Laini, S. Bagella, M. Bartoli, M. Cantonati, Water, 11(3), 402 (2019)

19. J. F. Mercure, M. A. Paim, P. Bocquillon, S. Lindner, P. Salas, P. Martinelli, J. M. P. Ribeiro, Renewable and Sustainable Energy Reviews, 105, 230 (2019)

20. J. Abrham, W. Strielkowski, M. Vošta, J. Šlajs, Agricultural Economics, 61(10), 450 (2015)

21. J. P. Thérien, V. Pouliot, Review of International Political Economy, 27(3), 612 (2020)

22. P. Koudelková, W. Strielkowski, D. Hejlová, Danube: Law, Economics and Social Issues Review, 6(1), 25 (2015)

23. K. Liczmańska-Kopcewicz, K. Mizera, P. Pypłacz, Sustainability, 11(20), 5808 (2019)

24. I. Cabelkova, W. Strielkowski, M. Mirvald, Transformations in Business \& Economics, 14(1), 65 (2015)

25. N. Kolleck, Environmental Education Research, 25(11), 1635 (2019)

26. E. Boeren, International Review of Education, 65(2), 277 (2019) 